\title{
Comparative Analysis of Power Loss using Different Modulation Techniques in Modular Multilevel Converter

\author{
${ }^{\text {"1 }}$ Preeti V. Kapoor, ${ }^{2}$ Mohan M. Renge, ${ }^{3}$ Sonali Rangari \\ 1,2,3 Shri Ramdeobaba College of Engineering and Management, Nagpur \\ Email: ${ }^{1}$ kapoorpv@rknec.edu, ${ }^{2}$ rengemm@rknec.edu, ${ }^{3}$ rangaris@rknec.edu
}

Received: 06th October 2019, Accepted: 20th November 2019, Published: 31st December 2019

\begin{abstract}
The application of voltage source inverter in medium and high power application is increasing extremely. Multilevel converters reduces the height of voltage steps at converter output and thus also $\mathrm{dv} / \mathrm{dt}$ and voltage harmonics. In high power applications high efficiency of converter is the most important aspect. Hence the power loss analysis has to be carry out at early stage of converter design. Power loss evaluation of multilevel converter is much more complicated as compared to two level inverter. This paper provides the software-based solution to calculate the power loss in semiconductor switch. Modular Multilevel Converter (MMC) an emerging topology in multilevel converter is considered for study. It also presents the comparison of power loss analysis with different pulse width modulation technique eliminating the same order of harmonics. The analysis has been carried out in three phase three level MMC driving high power medium voltage three phase induction motor. The converter is controlled by high switching frequency technique i.e. Sinusoidal Pulse Width Modulation (SPWM) and low switching frequency technique i.e. Selective Harmonic Elimination Pulse Width Modulation (SHE-PWM) technique. Comparison in regards with power loss and converter efficiency has been presented. Simulation has been carried out in MATLAB-SIMULINK providing the software-based solution to find the conduction and switching loss in a switch.
\end{abstract}

Keywords

Modular Multilevel Converter, Induction Motor, Conduction Loss, Switching Loss, SPWM, SHE-PWM.

\section{Introduction}

Multilevel converters are becoming more and more popular solution in medium voltage drives. Many topologies under multilevel converters were presented as in [1-2]. Among the various multilevel converters topologies, MMC is gaining more popularity in the industry and the academics for research mainly due to its modular structure, high scalability to reach different voltage levels, redundant construction, longer maintenance intervals, improved reliability, and higher efficiency. It was first proposed by Lesnicar and Marquardt in 2003. [3] MMC is finding more opportunities in area of variable speed drives since efficiency improvement in this area is required $[4,5]$ and hence it is chosen for study.

Design of a converter involves some factors such as power semiconductor, switching frequency selection and passive component design. Power Loss is one of the key practical issues which may influence the design consideration. Controlling drive with power electronics circuitry involves switching of semiconductor devices. There are mainly four types of the losses which occurs during functioning of a switch. These are i) Conduction loss ii) Switching loss iii) OFF-state loss and iv) Gate loss. This paper provides the software-based solution to find conduction loss and switching occurring in the switch during its operation as explained by [6]. OFF state and Gate loss is very small and hence neglected in the analysis. Loss in the switch directly affects heat generation and with increase in switching frequency there will be more EMI problems. As MMC deals with medium - voltage high- power applications, the rating of power semiconductor devices will be very high. Hence simulation is carried out in high power medium voltage induction motor. This paper discusses about the switching frequency required to eliminate same order of harmonics component with both SPWM and SHEPWM modulation technique. It was found that switching frequency required in SPWM technique to eliminate upto $13^{\text {th }}$ order harmonics is $1050 \mathrm{~Hz}$ and that to requires in SHE-PWM to eliminate upto same order of frequency is $500 \mathrm{~Hz}$. Comparative analysis of power loss and converter efficiency is carried out with both techniques with this harmonic elimination consideration. Results were compared and presented suggesting suitable modulation technique than be applied to MMC which can reduce the total power loss and improves converter efficiency.

\section{Modular Multilevel Converter}

The basic structure of three-phase MMC is shown in Fig. 1. One phase (or Leg) of MMC contains an upper arm and lower arm. Each arm consists of series connected identical submodules ' $N$ ' and an arm inductance ' $L$ arm'. Submodules are made of IGBT half-bridge modules supplied with dc-bus capacitor ' $\mathrm{C}$ '. The structure of submodule is shown in Fig. 2. In a submodule, switches $S_{1}$ and $S_{2}$ works in opposite way. When $S_{1}$ is $O N, S_{2}$ is $\mathrm{OFF}$ and vice versa. When $\mathrm{S}_{2}$ is $\mathrm{ON}$, output voltage ' $V o$ ' gives zero value. When $\mathrm{S}_{1}$ is $\mathrm{ON}$, output voltage ' $V o$ ' 
becomes equal to submodule capacitance voltage ' $V c$ '. The number of output voltage levels for conventional multilevel converter topology is fixed as the name suggest, but it is not the case with MMC. The MMC with ' $N$ ' submodules in lower or upper arm cannot be said ' $N+1$ ' level converter. However, it can either produce ' $N+1$ ' or ' $2 N+1$ ' level output with proper choice of switching pattern. In this paper study has been carried out with ' $2 N+1$ ' level output MMC with modified configuration as in $[7,8]$.
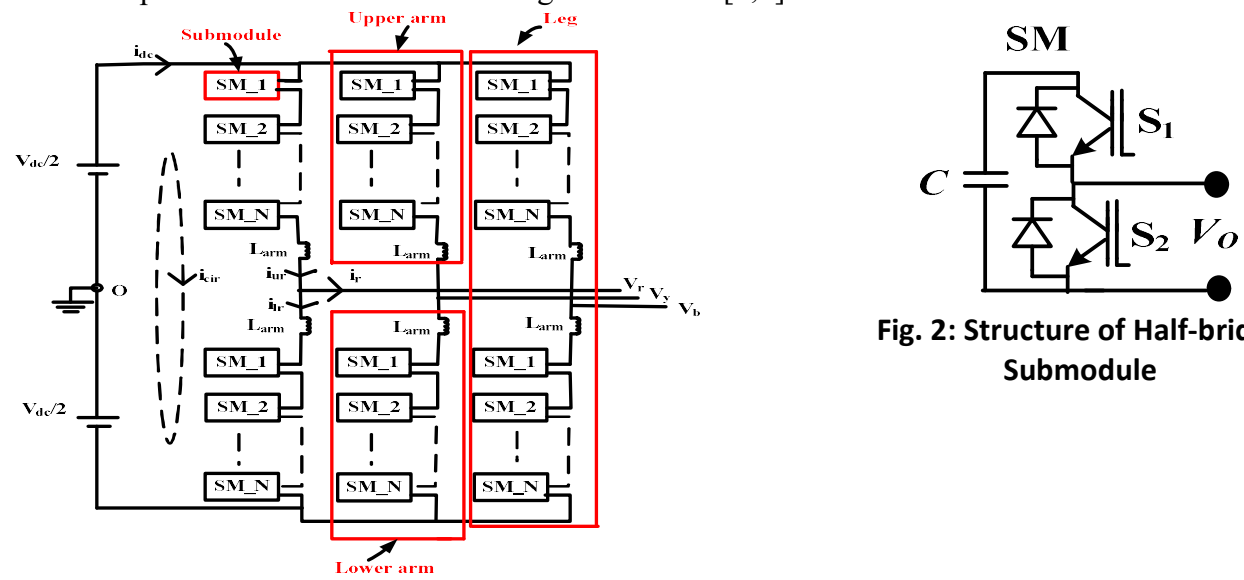

Fig. 2: Structure of Half-bridge Submodule

Fig. 1: Basic Structure of Three-phase MMC

\section{Methodology \\ Power Loss Evaluation}

In high power applications, designing of any converter involves selection of rating of semiconductor switches to optimize the size required and selection of suitable switching frequency to minimize the power loss. The study focuses on calculation of conduction and switching loss by applying both SPWM and SHE-PWM technique in a model of three phase three level MMC driving three phase medium voltage high power induction motor rated $1.6 \mathrm{MW}, 3.3 \mathrm{kV}$. It was observed that maximum current which can flow through a switch is $1000 \mathrm{~A}$ and for this range of current maximum voltage rating available for an IGBT in market is FZ1500R33HL3. Therefore, the switching device considered for the analysis is IGBT of type FZ1500R33HL3, which has a blocking voltage of $3.3 \mathrm{kV}$ and maximum forward current $1500 \mathrm{~A}$. Generally, IGBT voltage is de-rated to around $50 \%-60 \%$. Hence $3.3 \mathrm{kV}$ rating IGBT limits the submodule voltage to $1.5 \mathrm{kV}-2 \mathrm{kV}$. So, it was assumed that each submodule consists of three switches in series and the results presented considers this assumption.

A] Conduction Loss Calculation

It is defined as the loss which occurs in the semiconductor device when it is in on state and conducting current. The conduction losses for the IGBT and freewheeling diode are the product of the current flowing through the collector or anode ( $I_{C}$ for main switch current and $I_{D}$ for diode current) and saturation voltage or on state voltage ( $V_{c e}$ for IGBT and $V_{D}$ for diode) over the conducting period. The conduction power loss is calculated by (1) for IGBT and by (2) for the diode.

$P_{\text {con-IGBT }}=\frac{1}{T} \int_{0}^{T}\left[V_{c e} \times I_{c}\right] d t$

$P_{\text {con-Diode }}=\frac{1}{T} \int_{0}^{T}\left[V_{D} \times I_{D}\right] d t$

where, ' $T$ ' is the switching cycle.

The total conduction power losses are calculated by:

$P_{\text {con-total }}=P_{\text {con-IGBT }}+P_{\text {con-Diode }}$

Here, the on-state voltage can be expressed by a quadratic equation which is in terms of the on-state current. The quadratic equation is found using curve fitting tool in MATLAB-SIMULINK using actual characteristics given in device datasheet as shown in Table 1. The datasheet of this IGBT is referred in [9]. Each device is associated with two quadratic equation, one for the IGBT and other for the diode. Figure 3 shows the block diagram of conduction loss calculation. 


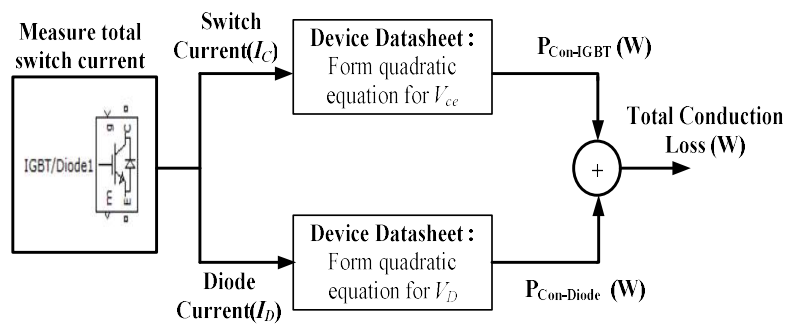

Fig.3: Block Diagram for Conduction Loss Calculation

\section{B] Switching Loss Calculation}

In real power semiconductors, current commutation cannot occur instantaneously, and therefore, switches simultaneously experience high voltage and high current during switching moments. This condition creates switching loss. It is the loss which occurs during switching of device, which includes both turn-on and turn-off processes. It happens in IGBT as well as in diode. This condition creates switching loss. Datasheets include switching loss information as $E_{\text {on }}-I_{C}$ for IGBT turn-on, $E_{\text {off }} I_{C}$ for IGBT turn-off and $E_{\text {rec }}-I_{D}$ for diode reverse recovery (turn-off) graphs. Turn-on loss in diode is normally neglected due to its fast conduction during forward bias condition. The turn on and turn-off power loss for the main switch are given by (4) and (5) respectively and reverse recovery power loss for the diode is calculated by (6).

$P_{\text {on }}=\frac{1}{T} \sum\left[E_{\text {on }} \times I_{c}\right] f_{S}$

$P_{\text {off }}=\frac{1}{T} \sum\left[E_{\text {off }} \times I_{c}\right] f_{S}$

$P_{\text {rec }}=\frac{1}{T} \sum\left[E_{\text {rec }} \times I_{D}\right] f_{S}$

where $f_{S}$ is switching frequency. The total switching power losses are calculated by

$P_{S W-\text { Total }}=P_{\text {on }}+P_{\text {off }}+P_{\text {rec }}$

The switching losses happen as a result of energy loss during the transition and switching frequency. From the device datasheet, energy factor ' $K$ ' is obtained by dividing energy from switch current. The quadratic equations for $K_{I G B T-O N}$ and $K_{I G B T-O F F}$ in terms of on state current are again found by using curve fitting tool in MATLABSIMULINK. Similarly, quadratic equation for $K_{\text {Diode-rec }}$ is found in terms of diode current based on actual characteristics given in device datasheet. Energy factor curves when multiplied by the switching current gives energy loss, which in turn when multiplied by the switching frequency gives power loss. If the blocking voltage is different, normalization factor is used to adjust as explained by [10]. Figure 4 shows the block diagram of switching loss calculation. Table 1 gives equations for a selected IGBT switch obtained from curve fitting tool of MATLAB software. Finally, the total power loss is sum of all conduction and switching power losses and computed by

$P_{\text {loss-Total }}=P_{\text {con-Total }}+P_{S W-\text { Total }}$

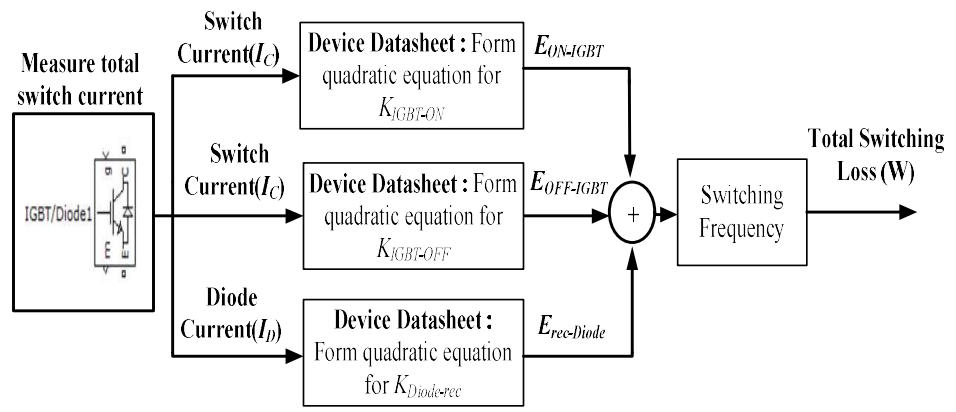

Fig.4: Block Diagram of Switching Loss Calculation

\begin{tabular}{|c|}
\hline$V_{c e}=-1.8 \times 10^{-7} I_{c}^{2}+0.0016 \times I_{c}+0.99$ \\
\hline$V_{D}=-1.8 \times 10^{-7} I_{D}^{2}+0.0013 \times I_{D}+0.73$ \\
\hline$K_{I G B T-O N}=7.7 \times 10^{-7} I_{c}^{2}-0.0023 \times I_{c}+3.9$ \\
\hline$K_{I G B T-O F F}=4.9 \times 10^{-7} I_{c}^{2}-0.002 \times I_{c}+3.8$ \\
\hline$K_{I G B T-r e c}=1.5 \times 10^{-6} I_{D}^{2}-0.0069 \times I_{D}+8.6$ \\
\hline
\end{tabular}

Table 1: IGBT Curve Fitted Equation Obtained from Datasheet (considering the ambient temperature $125^{\circ} \mathrm{C}$ ) 
Simulation Results and Comparative Analysis

The above topology was simulated by applying both SPWM and SHE-PWM technique separately with different switching frequency so as to eliminate up to $13^{\text {th }}$ harmonic component. Simulation parameters of motor as referred from [11] and converter parameters used in MATLAB -SIMULINK is as shown in Table 2. The current waveform of a single submodule obtained after simulation with both the techniques is shown in Fig. 5 and Fig. 6 respectively. In MATLAB model, IGBT current and diode current need to be obtained separately. By measuring on-state device current, the positive portion is separated representing current flowing through IGBT and negative portion is representing current flowing through diode. With this separated current, conduction losses for the IGBT and diodes are calculated as per the procedure depicted in block diagram shown in Fig. 3. Similarly, switching losses are calculated as per the block diagram shown in Fig. 4.

\begin{tabular}{|c|c|}
\hline $\begin{array}{c}\text { Motor Rated Power, Line Voltage, Rated Current, Rated } \\
\text { Speed }\end{array}$ & $\begin{array}{c}1.6 \mathrm{MW}, 3.3 \mathrm{kV}, 356 \mathrm{~A}, 596 \\
\mathrm{rpm}\end{array}$ \\
\hline Fundamental frequency & $50 \mathrm{~Hz}$ \\
\hline Stator resistance $\left(R_{s}\right)$, Rotor resistance $\left(R_{r}\right)$ & $57.61 \mathrm{~m} \Omega, 48.89 \mathrm{~m} \Omega$ \\
\hline Stator leakage inductance $\left(L_{/ s}\right)$, Rotor leakage inductance $\left(L_{l r}\right)$ & $2.544 \mathrm{mH}, 1.881 \mathrm{mH}$ \\
\hline Mutual inductance $\left(L_{m}\right)$ & $40.01 \mathrm{mH}$ \\
\hline Submodule voltage $\left(V_{d c}\right)$ & $5.5 \mathrm{kV}$ \\
\hline Arm inductane $\left(L_{a r m}\right)$ & $3 \mathrm{mH}$ \\
\hline Modulation index $(M I)$ & 0.9 \\
\hline Switching frequency $\left(f_{s}\right)$ & $1050 \mathrm{~Hz}$ \\
\hline Number of Submodule in each arm $(N)$ & 01 \\
\hline
\end{tabular}

Table 2 : Simulation Parameters of Converter and Motor of Higher Rating
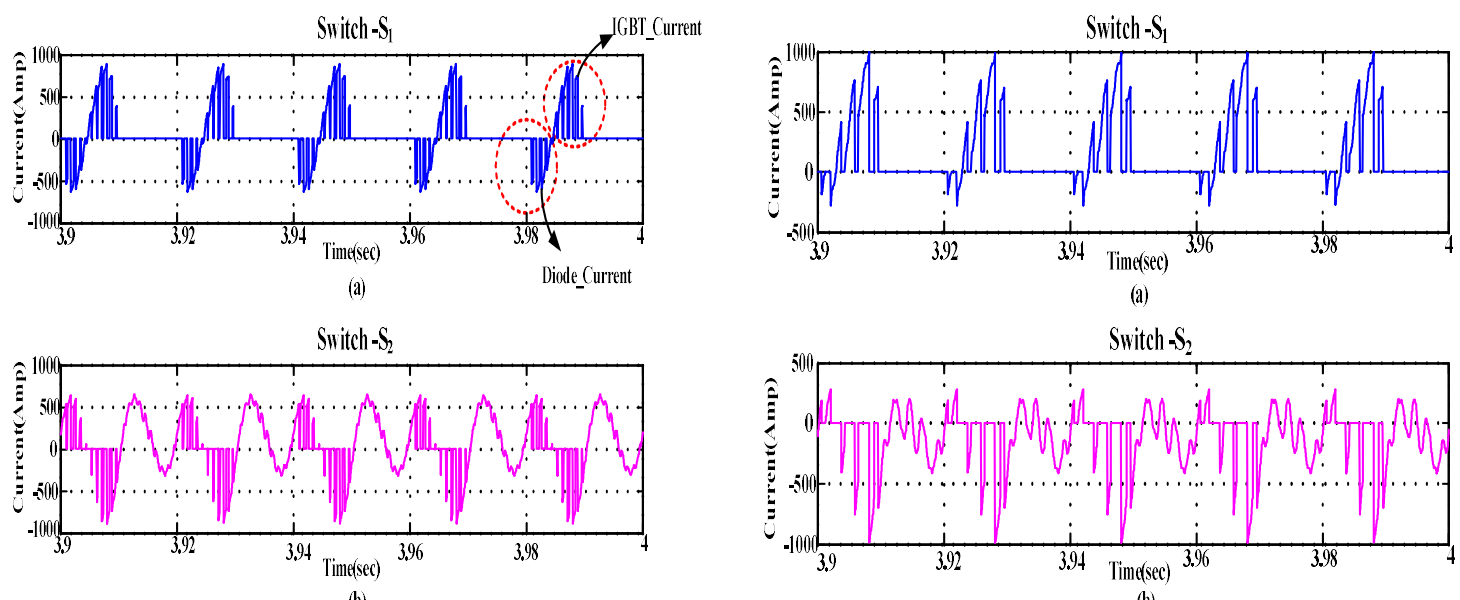

(b)

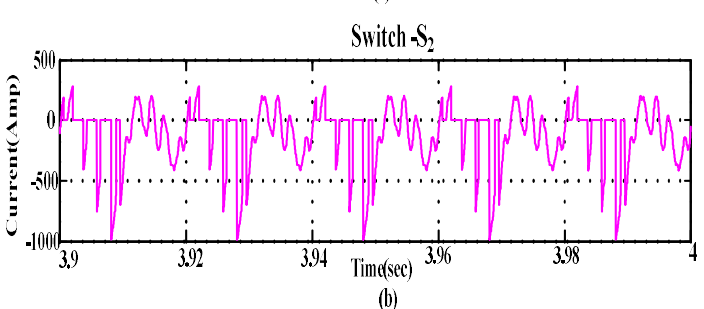

Fig.6: Current Waveform through One Submodule with SHE-PWM Technique: (a) Upper Switch (b) Lower Switch

Table 3 shows the comparative analysis based on elimination up to $13^{\text {th }}$ harmonic component with both the modulation techniques. It is observer that percentage loss in inverter is almost double with SPWM technique as compared to SHE-PWM technique. From Fig. 5 and 6 it is clear that SHE-PWM technique not only helps in reducing switching losses but also reduces conduction loss. 


\begin{tabular}{|l|l|l|}
\hline Comparison Parameter & SPWM Technique & SHE-PWM Technique \\
\hline Switching frequency & $1050 \mathrm{~Hz}$ & $500 \mathrm{~Hz}$ \\
\hline Total power loss [kW] & 66.76 & 22.83 \\
\hline Loss in inverter w.r.t output power [\%] & 4.17 & 2.15 \\
\hline Inverter Efficiency [\%] & 95.99 & 98.58 \\
\hline
\end{tabular}

Table 3: Comparative Analysis based on Elimination up to $13^{\text {th }}$ Harmonic Component

\section{Conclusion}

Multilevel converters are finding many economic and technical advantages in industries and utility applications. Under various multilevel topologies, Modular Multilevel Converter is emerging as a most popular topology in the field of high-power medium voltage applications. It is critical to evaluate loss in multilevel converter. Among various losses, conduction and switching loss is most dominating. This paper provides simple, efficient and easy implementation of software-based method to evaluate conduction and switching losses of each device. Losses of each device is added to find the total loss and hence converter efficiency is calculated. Comparison of power loss is carried out with both SPWM and SHE-PWM technique applied to three phase three level MMC driving high power medium voltage related induction motor. Comparison is made on the basis of eliminating upto $13^{\text {th }}$ order of harmonics with both the technique. It is observed that percentage loss in inverter with SHEPWM technique is almost reduced by $50 \%$ as compared to SPWM technique. Hence, SHE-PWM modulation technique is the most recommended method for controlling inverter as this technique has lower switching losses and less EMI problems. In addition, it eliminates lower order harmonics and hence minimizes the filter size at inverter output.

\section{References}

1. J. S. Lai and F. Z. Peng 1996, "Multilevel converters - A new breed of power converters, " IEEE Trans. Ind. Appl., vol. 32, no. 3, pp. 509-517.

2. J. Rodríguez, J. S. Lai and F. Z. Peng 2002, "Multilevel inverters: A survey of topologies, controls, and applications," IEEE Transactions on Industrial Electronics, vol. 49, no. 4, pp. 724-738.

3. A. Lesnicar and R. Marquardt 2003, "An innovative modular multilevel converter topology suitable for a wide power range," 2003 IEEE Bologna PowerTech - Conference Proceedings, vol. 3, pp. 272-277.

4. M. Hagiwara, K. Nishimura and H. Akagi 2010, "A medium-voltage motor drive with a modular multilevel PWM inverter," IEEE Transactions on Power Electronics, vol. 25, no. 7, pp. 1786-1799.

5. A. Antonopoulos, L. Ängquist, S. Norrga, K. Ilves, L. Harnefors and H. P. Nee 2014, "Modular multilevel converter AC motor drives with constant torque from zero to nominal speed," IEEE Transactions on Industry Applications, vol. 50, no. 3, pp. 1982-1993.

6. Alamri Baseem, and Mohammad Darwish 2015, "Power Loss Investigation for 13-level cascaded hbridge multilevel inverter." J. Energy Power Sources, vol. 2, no. 6, pp. 230-238.

7. Preeti V. Kapoor, Mohan M. Renge 2018, "Comparative Analysis of Modular Multilevel Converter with different Modulation technique for Control of Induction Motor Drive", Springer journal of Microsystem Technologies.

8. Preeti V. Kapoor, Mohan M. Renge 2017, “Operation of Modular Multilevel Converter Drive with reduced Submodules and DC supply", IEEE-International Conference on Energy, Communication, Data Analytic and Soft Computing(ICECDS-2017), Chennai, India, August $1^{\text {st }}-2^{\text {nd }}$.

9. Infineon Technologies, "FZ1500R33HL3", datasheet,Technical Information

10. Ertürk, Feyzullah, and Ahmet M. Hava, 2015, "A detailed power loss analysis of modular multilevel converter." in Applied Power Electronics Conference and Exposition (APEC), 2015 IEEE, pp. 16581665. IEEE.

11. J. Scoltock, T. Geyer and U. K. Madawala 2013, "A comparison of Model Predictive Control Schemes for MV Induction Motor Drives," IEEE transaction on Industrial Informatics 9, no. 2. 